\title{
A Comparative Study of the Effect of Some Mineral and Plant Oils on the Two Spotted Spider Mite Tetranychus urticae Koch (Acari: Tetranychidae)
}

\author{
S. A. A. AMER, S. A. SABER and F. M. MOMEN \\ Plant Protection Department, \\ National Research Center, Dokki, Cairo, Egypt
}

\begin{abstract}
The direct toxicity of some mineral and plant oils to the eggs and females of the two spotted spider mite Tetranychus urticae Koch was tested. KZ oil was toxic to the egg stage compared to adult female. In contrast, Natur'l oil has a close toxic effect for both stages of T. urticae. Bio-dux oil was proved to be toxic to adult female and relatively in toxic to egg stage. Females of $T$. urticae suffered a depression in reproduction and shortened longevity when kept on plant leaves previously treated with different oils. Laboratory studies indicated that the vegetable oil Natur'l oil was effective on all biological aspects of T. urticae studied.
\end{abstract}

Keywords: Acari, mineral oils, plant oil, T. urticae.

The two spotted spider mite, Tetranychus urticae Koch, has been evaluated as a potentially serious pest of many agricultural crops (Jeppson et al., 1975; Helle and Sabelis, 1985). Mineral spray oils of various qualities have traditionally been used as curatives to down small insect and mites (Hely et al., 1982; Davidson et al., 1991). These oils are cheaper and less phytotoxic than their predecessors (Riehl, 1969, 1981; Beattie et al., 1989), as well as, no empirically demonstrated resistance by pests. Modern petroleum spray oils meet the criteria better than most alternatives. They are ideally suited to IPM and organic farming (Davidson et al., 1991) and resistance is unlikely (Beattie and Smith, 1996).

A few published data on the susceptibility of mite pests to oils are limited to citrus red mite Panonychus citri (McGregor) (Riehl et al., 1958; Trammel, 1965; Herron et al., 1995), the European red mite Panonychus ulmi (Kock) as well as the spider mites Eutetranychus orientalis (Klein) and T. urticae (Osman, 1997; Herron et al., 1998).

The immediate goal of the present study is to evaluate the efficacy of some mineral and plant oils that can be used in integrated control of T. urticae, the main acarine pest of vegetables.

\section{Materials and Methods}

Mineral oils

Sol EC: [it is a solar cut petroleum oil fraction prepared as emulsifiable concentrate contained $96.62 \%$ (v./v.) base oil], Capl-1: (it is sulfonated solar oil prepared as emulsifiable concentrate, registered by Central Agriculture Pesticides Laboratory), Capl-2: [lubrication cut of petroleum oil fraction prepared as emulsifiable concentrate 
contained mineral oil $96.62 \%$ (v./v.)], KZ oil: [prepared as emulsifiable concentrate contained 95\% Paraffin oil (w./w.)], Citrole: (made from a biodegradable paraffin as an emulsifiable formulation permitting ease of mixing with water), Kemesol: [local mineral oil prepared as emulsifiable concentrate contained $95 \%$ (v./v.) base oil], Bio-dux: [15\% potassium oleate $\left(150 \mathrm{~g} / \mathrm{kg}\right.$ at $\left.\left.20{ }^{\circ} \mathrm{C}\right)\right]$.

Vegetable oil

Natur'l oil: [Natural vegetable oil 93\% (w./v.)].

COLLECTION AND MAINTENANCE OF MITES

The two spotted spider mite T. urticae were collected from infested cucumber leaves from plantations at Giza and reared on Lima bean [Phaseolus vulgaris (L.)] under standard laboratory conditions $\left(25 \pm 2{ }^{\circ} \mathrm{C} ; 65 \pm 5 \% \mathrm{R}\right.$. H. $)$.

\section{Toxicity bioassay}

\section{DIRECT EFFECT ON ADULT FEMALES}

Adult females of T. urticae were confined on the lower surfaces of detached raspberry leaves $(3 \mathrm{~cm}$ in dia.) while the upper surfaces were placed on cotton saturated with water. Mites were sprayed with different oils using a glass atomizer.

For each oil, 5 concentrations were tested in addition to a control. A total of 30 adult female spider mites were used in each treatment and each experiment was repeated 3 times. Mites that did not walk when gently prodded were counted as dead. Mortality was recorded $48 \mathrm{~h}$ after application.

\section{DIRECT EFFECT ON EGG STAGE}

The direct effect on egg stage was studied by confining to females on leaf discs for $24 \mathrm{~h}$, then removed. These discs were sprayed with deposited eggs ( $24 \mathrm{~h}$ old $)$ in a series of concentrations for $50 \mathrm{sec}$., and allowed to dry. Observations on viability were made twice a day. Eggs that had not detached after 7 days since oviposition were considered non-viable. The experiment was repeated 3 times. A control was included in each experiment.

Corrected mortality counts according to Abbot's formula (1925), then submitted to probit analysis using Finney (1952)

$$
\text { Relative toxicity }=\frac{\mathrm{LC}_{50} \text { of the most active oil } \times 100}{\mathrm{LC}_{50} \text { of certain oil }}
$$

\section{Biological Tests}

BIOASSAY FOR RESIDUAL ACTIVITY

In a third series of experiments, the residual activity of each oil was investigated. Leaf discs were dipped for $60 \mathrm{sec}$ in the $\mathrm{LC}_{50}$ of each of the aforementioned oils. The leaf discs were placed on a layer of wet cotton wool on top of a sponge in a tray with a sufficient amount of water to keep the sponge wet. One newly emerged adult female spider mite was placed on each disc. Untreated discs were used as a control. Each treatment was replicated 20 times. 
Statistical analysis were carried out using F test. Observations on different biological aspects were recorded daily.

\section{Results and Discussion}

\section{Toxicity to adult females}

The data obtained in Table 1 show that Citrole oil was the most toxic to adult female, while $\mathrm{KZ}$ oil was the least. $\mathrm{The} \mathrm{LC}_{50}$ values of the tested oils toxicity were in descending order of effectiveness as follows: Citrole, Kemesol, Natur'l oil, Capl-1, Sol, Capl-2, Bio-dux and KZ oil. Herron et al. (1998) reported that the petroleum spray oil C 23 was generally more efficacious on adult female P. ulmi and T. urticae than C 21 oil. Research carried out by Osman (1997) indicated that the petroleum oils (Albulium 80\% EC, KZ 95\% EC, Shokrona super EC 95\%) were more toxic to adult females of $E$. orientalis than that of T. urticae.

\section{Table 1}

Toxicity of some mineral and plant oils against adult females T. urticae

\begin{tabular}{lccccc}
\hline & & & & \multicolumn{2}{c}{ Relative toxicity at } \\
\cline { 5 - 6 } Materials & $\mathrm{LC}_{50}$ & $\mathrm{LC}_{90}$ & Slope & CC $_{50}$ & LC $_{90}$ \\
\hline Citrole & 0.975 & 9.598 & 1.29 & 100 & 59.64 \\
Kemesol & 1.055 & 5.724 & 1.77 & 92.42 & 100 \\
Natur'l oil & 2.055 & 12.85 & 1.61 & 47.45 & 44.54 \\
Capl-1 & 3.195 & 10.27 & 2.52 & 30.52 & 55.74 \\
Sol & 3.878 & 10.10 & 3.07 & 25.14 & 56.67 \\
Capl-2 & 4.336 & 8.628 & 4.28 & 22.49 & 66.34 \\
Bio-dux & 4.812 & 9.378 & 4.42 & 20.26 & 61.04 \\
KZ oil & 5.731 & 73.89 & 1.15 & 17.01 & 7.75 \\
\hline
\end{tabular}

\section{Toxicity to egg stage}

$\mathrm{KZ}$ and Citrole oils have been shown to be toxic oils on egg stage of T. urticae (Table 2), Tested oils can be arranged according to their $\mathrm{LC}_{50}$ values for egg stage in the following descending order of effectiveness: KZ, Citrole, Sol, Capl-1, Kemesol, Capl-2, Natur'l oil and Bio-dux. Results from Fig. 1 show that egg stage more sensitive to different oils than adult stage, except for the Bio-dux which was toxic to adult stage than egg stage $\left(\mathrm{LC}_{50}=4.812\right.$ and $11.46 \%$ respectively). Results indicated also, that $\mathrm{KZ}$ oil was more toxic to egg stage than to adult stage $\left(\mathrm{LC}_{50}=0.20\right.$ and $5.731 \%$ respectively).

It is worth mention also that the toxicity effect of Kemesol oil and Natur'l oil on both stages were very close $\left(\mathrm{LC}_{50}=1.055\right.$ and $0.638 \%$; and $\mathrm{LC}_{50}=2.055$ and $1.494 \%$ respectively). Osman (1997) demonstrated that the response of egg stage of T. urticae and E. orientalis to the mineral oils varied according to their age. 
Table 2

Toxicity of some mineral and plant oils against egg stage of T. urticae

\begin{tabular}{lccccc}
\hline & & & & \multicolumn{2}{c}{ Relative toxicity at } \\
\cline { 5 - 6 } Materials & $\mathrm{LC}_{50}$ & $\mathrm{LC}_{90}$ & Slope & $\mathrm{LC}_{50}$ & $\mathrm{LC}_{90}$ \\
\hline KZ oil & 0.20 & 0.642 & 2.52 & 100 & 78.66 \\
Citrole & 0.232 & 0.505 & 3.79 & 86.21 & 100 \\
Sol & 0.579 & 1.191 & 4.09 & 34.54 & 42.40 \\
Capl-1 & 0.618 & 1.846 & 2.69 & 32.36 & 27.36 \\
Kemesol & 0.638 & 1.614 & 3.17 & 31.35 & 31.29 \\
Capl-2 & 0.878 & 3.513 & 2.13 & 22.78 & 14.38 \\
Natur'l oil & 1.494 & 12.36 & 1.40 & 13.39 & 4.09 \\
Bio-dux & 11.46 & 32.26 & 2.85 & 1.75 & 1.57 \\
\hline
\end{tabular}

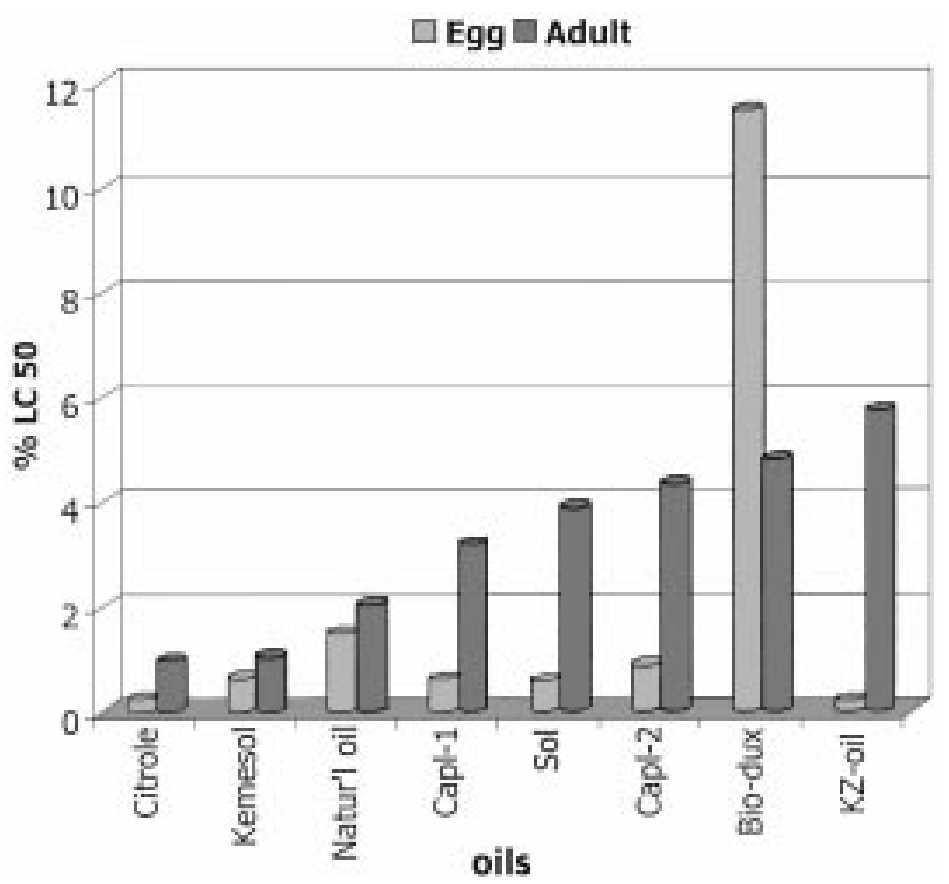

Fig. 1. Toxicity of some mineral and plant oils against egg stage and adult females of T. urticae

The greater susceptibility to the petroleum spray oils of $P$. ulmi compared to $T$. urticae was reported by Herron et al. (1998) as well as adult female of P. citri were significantly more susceptible than adult female T. urticae (Herron et al., 1995). They suggested that the different responses might be related to variation in the sizes and distribution of dorsal setae and the structure and functioning of their respiratory systems. 


\section{Biological tests}

\section{BIOASSAY FOR RESIDUAL ACTIVITY}

It is clear from Table 3 that the mineral and plant oils treatment used, prolonged the preoviposition period and showed highly significant effects at Natur'l oil, Capl-1 and Bio-dux oils. The incubation period was affected also and showed highly significant effects at citrole, Kemesol and Natur'l oils. On the other hand, the $\mathrm{LC}_{50}$ treatment of each oil used, shorted the female longevity and the female fecundity was significantly reduced. The vegetable oil, Natur'l oil was generally highly efficacious on all biological aspects of the adult female $T$. urticae (Table 3 ).

\section{Table 3}

Effect of tested oils ( $\mathrm{LC}_{50}$ conc.) on different biological aspects of T. urticae

\begin{tabular}{|c|c|c|c|c|c|}
\hline \multirow{2}{*}{\multicolumn{2}{|c|}{ Materials }} & \multicolumn{4}{|c|}{ Biological aspects, periods in days } \\
\hline & & $\begin{array}{c}\text { Pre-oviposition } \\
\pm \text { S.E. }\end{array}$ & $\begin{array}{c}\text { Incubation } \\
\pm \text { S.E. }\end{array}$ & $\begin{array}{c}\text { Female } \\
\text { longevity } \pm \text { S.E. }\end{array}$ & $\begin{array}{c}\text { Total No. of } \\
\text { eggs/female } \pm \text { S.E. }\end{array}$ \\
\hline \multicolumn{2}{|l|}{ Citrole } & $1.4 \pm 0.11$ & $4.05 \pm 0.14^{* *}$ & $4.2 \pm 0.55^{* *}$ & $4.95 \pm 0.79^{* *}$ \\
\hline \multicolumn{2}{|l|}{ Kemesol } & $1.35 \pm 0.11$ & $3.6 \pm 0.11^{* *}$ & $3.8 \pm 0.42^{* *}$ & $7.9 \pm 0.78^{* *}$ \\
\hline \multicolumn{2}{|c|}{ Natur'l oil } & $2.2 \pm 0.27^{* *}$ & $3.55 \pm 0.21^{* *}$ & $5.4 \pm 0.54^{* *}$ & $1.9 \pm 0.31^{* *}$ \\
\hline \multicolumn{2}{|l|}{ Capl-1 } & $2.05 \pm 0.29^{* *}$ & $2.8 \pm 0.17$ & $5.5 \pm 0.53^{* *}$ & $8.7 \pm 1.82^{* *}$ \\
\hline \multicolumn{2}{|l|}{ Sol } & $1.4 \pm 0.18$ & $2.55 \pm 0.17$ & $2.8 \pm 0.14^{* *}$ & $2.05 \pm 0.23^{* *}$ \\
\hline \multicolumn{2}{|l|}{ Capl-2 } & $1.5 \pm 0.20$ & $2.75 \pm 0.18$ & $4.1 \pm 0.63^{* *}$ & $3.9 \pm 0.63^{* *}$ \\
\hline \multicolumn{2}{|l|}{ Bio-dux } & $2.1 \pm 0.19^{* *}$ & $2.5 \pm 0.15$ & $5.65 \pm 0.47^{* *}$ & $2.3 \pm 0.48^{* *}$ \\
\hline \multicolumn{2}{|l|}{$\mathrm{KZ}$ oil } & $1.7 \pm 0.21$ & $2.85 \pm 0.15$ & $4.2 \pm 0.51^{* *}$ & $1.7 \pm 0.24^{* *}$ \\
\hline \multirow[t]{2}{*}{ Control } & & $1.3 \pm 0.11$ & $2.5 \pm 0.11$ & $18.9 \pm 0.37$ & $74.9 \pm 0.93$ \\
\hline & 0.05 & 0.543 & 0.440 & 1.341 & 2.328 \\
\hline L.S.D. & 0.01 & 0.717 & 0.581 & 1.769 & 3.072 \\
\hline
\end{tabular}

${ }^{* *}$ High significant $\leq 0.01 \%$

Osman (1997) demonstrated that petroleum spray oils, Albulium 80\% EC, KZ 95\% EC, Shokorana super 95\% EC and Shokorana 95\% EC were significantly reduced the fecundity of both spider mites T. urticae and E. orientalis. The studies by Rae et al. (1999) on citrus psylla have shown that $0.5 \%$ petroleum oil sprays deter oviposition, and kill eggs and nymphs. They also showed that these sprays are as effective as omethoate and diflubenzuron (an IGR), both of which are currently used to control the pest in China. Rizk et al. (1999) reported the succes of the petroleum oils, Capl-1, Capl-2 and Sol-EC against adult of Tetranychus letoralis on cotton plant.

\section{Conclusion}

Pesticides must be carefully chosen and should only be used when natural enemies fail to keep pest population below economic thresholds. Unlike insecticides, oils are not acutely poisonous and generally kill by suffocation (Ebeling, 1959; Riehl, 1967). 
The ability of the two spotted spider mite to retract its stylophore and restrict air movement into the peritremes is thought to be related to its tolerance to toxic gases and its ability to withstand desiccation (Jeppson et al., 1975; Helle and Sabelis, 1985). The information presented here is based on laboratory experiments, and indicated that the vegetable oil (Natur'l oil), had a close toxicity effect on both stages, eggs and adult female as well as its effect on the biological aspects is promising. The results of the present study indicated that different mineral oils can be effective on the pest T. urticae.

Further field studies will indicate the possibility for using mineral and plant oils to control the pest mite in the field. According to Davidson et al. (1991), use of petroleum spray oils in low-volume sprays at lower rates per hectare than used conventionally, also reduce risk of phytotoxicity.

Much information is needed on the impact of different mineral and plant oils on natural enemies (insects and mites) associated with spider mites in the field.

\section{Literature}

Abbott, W. S. (1925): A method of computing the effectiveness of an insecticide. J. Econ. Ent. 18, 265-267.

Beattie, G. A. C. and Smith, D. (1996): Integrated pest management: Sustainable pest control for the future based on the past. Proc. Int. Soc. Citriculture 51-58.

Beattie, G. A. C., Roberts, E. A., Rippon, L. E. and Vanhoff, C. L. (1989): Phytotoxicity of petroleum spray oils to Valencia orange, Citrus sinensis (L.) Osbeck, in New South Wales. Aust. J. exp. Agr. 29, 273-282.

Davidson, N. A., Dibble, J. E., Flint, M. L., Marer, P. J. and Guye, A. (1991): Managing insects and mites with spray oils. Univ. Cal. Spec. Public. 3347.

Ebeling, W. (1959): Subtropical fruit pests. Univ. Cal., Div. Agric. Sci., Berkeley.

Finney, D. J. (1952): Probit analysis a statistical treatment of the sigmoid response curve. Cambridge University Press.

Helle, W. and Sabelis, M. W. (eds) (1985): Spider mites. Their biology, natural enemies and control. Elsevier, Amsterdam.

Hely, P. C., Pasfield, G. and Gellatley, J. G. (1982): Insects pests of fruit and vegetables in N. S. W. Inkata Press, Melbourne.

Herron, G. A., Beattie, G. A. C., Kallianpur, A. and Barchia, I. (1998): A potter spray tower bioassay of two petroleum spray oils against adult female Panonychus ulmi (Koch) and Tetranychus urticae Koch (Acari: Tetranychidae). Exp. App. Acarology 22, 553-558.

Herron, G. A., Beattie, G. A. C., Parkes, R. A. and Barchia, I. (1995): Potter spray tower bioassay of selected citrus pests to petroleum spray oil. J. Aust. Entomol. Soc. 34, 255-263.

Jeppson, L. R., Keifer, H. H. and Baker, E. W. (1975): Mites injurious to economic plants. Univ. Cal. Press: Berkeley, Los Angeles.

Osman, M. S. (1997): Petroleum oils as a component of integrated pest management of phytophagous mites. Arab-Gulf-J. Sci. Res. 15, 125-135.

Rae, D. J., Watson, D. W., Liang, W. G., Tan, B. L., Li, M., Huang, M. D., Ding, Y., Xiong, J. J., Du, D. P., Tang, J. and Beattie, G. A. C. (1999): Comparison of petroleum spray oils, abamectin, cartap, and methomyl for citrus leafminer (Lepidoptera: Gracillariidae) control in southern China. J. Econ. Ent. (in press).

Riehl, L. A. (1967): Characterization of petroleum oils for the control of pests of citrus. Agric. Food. Chem. 15, 878-882.

Riehl, L. A. (1969): Advances relevant to narrow-range spray oils for citrus pest control. Proc. 1st Int. Citrus Symp. 2, 897-907. 
Riehl, L. A. (1981): Fundamental consideration and current development in the production and use of petroleum oils. Proc. Int. Soc. Citriculture 2, 601-607.

Riehl, L. A., Ladue, J. P. and Rodriguez, J. L. Jr. (1958): Evaluation of representative California spray oils against citrus red mite and California red scale. J. Econ. Ent. 51, 193-195.

Rizk, M. A., El-Sisi, A. G., Badr, N. A. and Abdel-Halim, S. M. (1999): Controlling of cotton sucking pests using safe materials. 2nd Int. Conf. Pest Cont. Mansoura, Egypt, 211-221.

Trammel, K. (1965): Properties of petroleum oils in relation to toxicity to citrus red mite eggs. J. Econ. Ent. 58, 595-601. 